S.W. Mosko, D.T. Dowling, and D.K. Olsen,

\section{ABSTRACT}

HISTRAP, a proposed synchrotron-coolingstorage ring designed to both accelerate and decelerate very highly charged very heavy ions for atomic physics research, requires an If accelerating system to provide $\pm 2.5 \mathrm{kv}$ of peak accelerating voltage per turn while tuning through a 13.5:1 frequency range in a fraction of a second. A prototype half-wave, single gap rf cavity with biased ferrite tuning was built and tested over a continuous tuning range of $200 \mathrm{kHz}$ through $2.7 \mathrm{MHz}$. Initial test results establish the feasibility of using ferrite tuning at the required rf power levels. The resonant system is located entirely outside of the accelerator's $15 \mathrm{~cm}$ ID beam line vacuum enclosure except for a single rf window which serves as an accelerating gap. Physical separation of the cavity and the beam line permits in situ vacuum baking of the beam line at $3000 \mathrm{C}$.

\section{INTRODUCTION}

HISTRAP 1 is a proposed $46.8 \mathrm{~m}$ synchrotroncooler-storage ring optimized for advanced atomic physics research. It is injected with heavy ions from either the HHIRF 25 MV Tandem Accelerator or a dedicated $14.5 \mathrm{GHz}$ ECR source via an $0.25 \mathrm{MeV} / \mathrm{nucleon}$ RFQ linac. A design program is underway in which prototypes of major HiSTRAP components including an rf cavity, a dipole magnet2, and a beam line section have been fabricated, assembled, and tested.

In the standard high current operating mode, heavy ions from the tandem are injected into HISTRAP with a magnetic rigidity of about 1.0 $\mathrm{Tm}$ and with circulation frequencies between $2.0 \mathrm{MHz}$ for $12 \mathrm{ct}$ and 0.38 MHz for $23 \mathrm{U}^{43+}$. These ions are either acceierated to a maximum magnetic rigidity of $2.67 \mathrm{Tm}$ with circulation frequencies between $2.7 \mathrm{MHz}$ and $1.0 \mathrm{MHz}$, or decelerated to a minimum magnetic rigidity of $0.10 \mathrm{Tm}$ with circulation frequensies between $0.10 \mathrm{MHz}$ and $0.038 \mathrm{MHz}$. Other beam species are injected with a variety of charge-to-mass ratios and kinetic energies per nucleon. The longitudinal phase-space area of the injected beam depends upon its mass and kinetic energy per nucleon. This is particularly true for post-stripped tandem beams where the stripper foil thickness and resultant induced energy spread depend on the isotope. In fact, most of the rf cavity voltage is needed to provide phase space area for injected beams.

\section{RF REOUIREMENTS}

For all ion species of interest, the maximum required accelerating voltage is $2.5 \mathrm{kV}$ peak per turn. A tuning range between $0.2 \mathrm{MHz}$ and $2.7 \mathrm{MHz}$ is adequate using harmonic numbers between one and six. For operation with typical ions in the accelerating mode, the $r f$ tunes over most of the available range within

a period of about $0.5 \mathrm{~s}$. The tuning program must track with the dipole magnetic field of the synchrotron, in order to maintain constant beam radius during acceleration.

Given the required accelerating potential, the If system requirements appear to be quile modest. However, the required frequency swing is very large, and the relatively compact accelerator configuration and large aperture (15 cm) provide little space ( $1.3 \mathrm{~m}$ axially) for an accelerating system. Vacium requirements for HISTRAP are such that all beam line vacuum components must withstand baking at $3000 \mathrm{C}$. Consequently, rf system components which are not compatible with the baking process must be shermally isolated from the beam lines.

\title{
PROTOTIPE CAVITY
}

The selected rf cavity configuration has a ferrite loaded half wave coaxial resonator with a single accelerating gap as shown in figure 1. The center conductor is concentric with, but completely separate from, the beam line and accelerating gap except for retractable contact rings that establish electrical contact between the cavity and the accelerating gap, figure 2. When vacuum bake-out of the beam line is required, the contact rings are retracted so that the cavity components are thermally isolated from the beam line. water cooling on the center conductor is provided for removal of both normal if heating and heat radiated from the beam line during bake-out. A second set of contacts on the ends of the cavity are used to suppress if resonant modes on the beam line. Characteristics of the cavity are listed in table 1 .

The unusually wide tuning range for a single cavity accelerating system, cavity size limitations, and relatively low Erequency result in rather stringent requirements for

\section{Table 1}

\section{RF CAVITY CHARACTERISTICS}

Peak if voltage

Tuning range

Overall length

Beam tube diameter

Center conductor OD

outer conductor ID

Ferrite rings

Material

ID

OD

Thickness

Rings per cavity

Ferrite cooling

Ferrite permeability range

Peak ferrite bias current

Shunt capacitance required

Total peak cavity if drive power
2500 volts

0.2 to $2.7 \mathrm{HHz}$

1.2 meters

0.15 meters

0.254 meters

0.648 meters

TDK SY7 (NiZn)

0.3 meters

0.5 meters

0.025 meters 28

separators $200 \mathrm{mik} / \mathrm{cc}$

8 to 1400

3000 ampere turns $6000 \mathrm{pF}$

$20 \mathrm{~kW}$

\footnotetext{
Research Sponsored by the U.S. Department of Energy under contract DE-ACO5-840R21400 with Martin Marietta Energy Systems, Inc. 

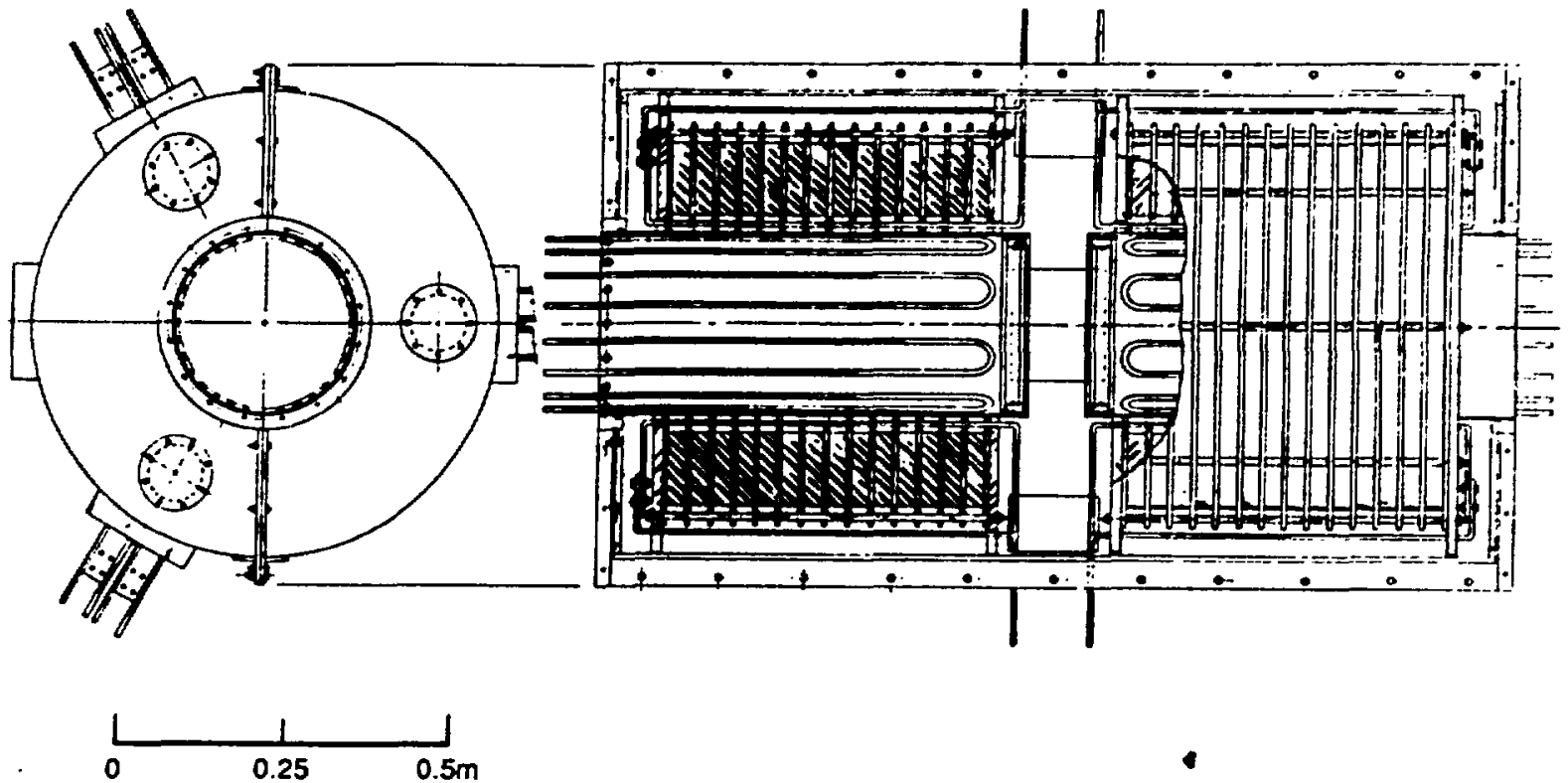

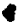

Fig. 1, A cut-a-way longitudinal view and an end view of the HISTRAR rf Cavity.

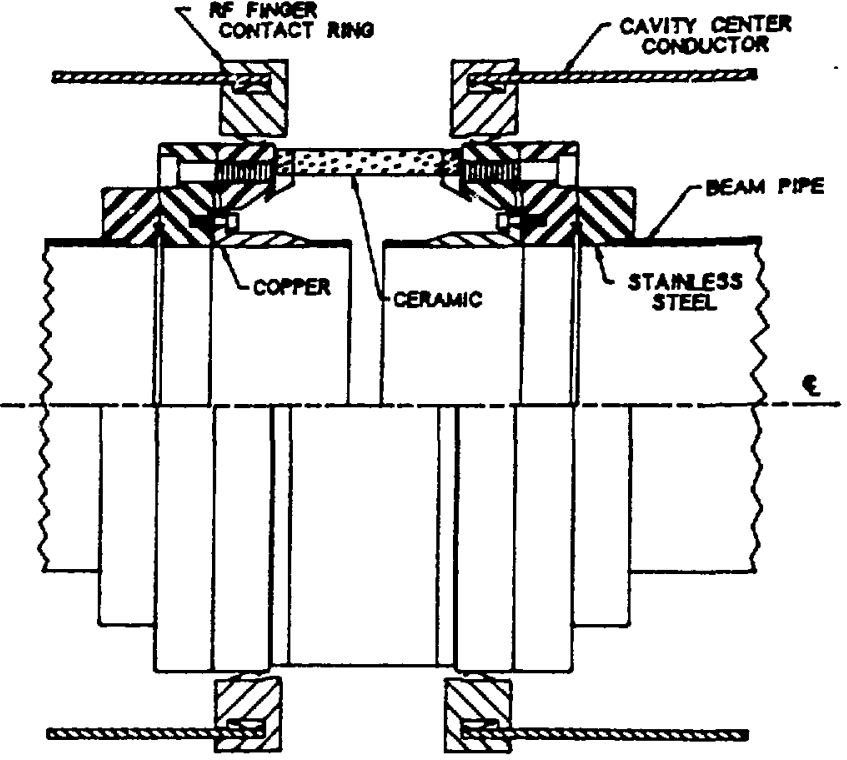

Fig. 2, A sectional view of the accelerating gap showing the gap insulator and the contact rings between the cavity and the beam line.

the ferrite load. Fortunately, the rf yoltage requirement is quite low. Nevertheless, SY7 ferrite has a low Curie Temperature, $90 \circ \mathrm{C}$, and a tendency to become unstable at moderate $r f$ excitation levels. The cavity was designed to hold as much ferrite as possible in order to minimize the rf power dissipation per unit of ferrite volume. The ferrite rings are separated by $6.4 \mathrm{~mm}$ thick copper rings which are water cooled by peripherally attached copper water lines. The expected ferrite temperature rise under full rf excitation is about $5^{\circ} \mathrm{C}$.

An array of 3 individual "figure 8 " bias windings produces up to 3000 ampere turns of bias field in the ferrite in order to swing the permeability from 1400 to 8 . Leads from each half winding are extended out of the cavity through the several ports in the cavity's outer conductor. External connections are used for closing each figure 8 and for placing the turns in series or parallel configurations. Space is available for up to 5 turns if more bias excitation is required.

\section{PROTOTYPE TEST RESULTS}

A prototype cavity was fabricated, assembled, and tested. The prototype has only 16 ferrite rings at this time which are sufficient to check most required characteristics. Figure 3 shows a photograph of the cavity partially assembled with the 16 rings in place. Ferrite specifications for the rings are listed in table 2. By operating the cavity with only 16 rings, the designed $r f$ field intensity levels in the ferrite are reached with about half of the normal cavity rf voltage. The required rf excitation power level is similarly reduced.

\section{Table?}

\section{FERRITE SPECIFICATIONS}

Initial permeability

RF excitation 1 oss at $0.2 \mathrm{HHz}$

and 275 gauss of rf field

RP excitation loss at $2.5 \mathrm{MHz}$

and 22 gauss of $f$ field

2500

$<0.06 \mathrm{\omega} / \mathrm{cc}$

$<0.06 \% / \mathrm{cc}$

The ferrite rings were tested individually to determine respective permeability, magnetization, and of loss characteristics. Typical values of initial permeability are between 2000 and 3000 , and rf 1053 characteristics are safely within specification. Measurement of magnetization characteristics was not successful on individual rings due to intrinsic inductances in the test circuit. However. values of permeability calculated from cavity tuning data, shown in figure 4 , indicate that 3000 ampere turns of bias is sufficient to drive the permeability down to less than 8 . 


\section{DISCLAIMER}

This report was prepared as an account of work sponsored by an agency of the United States Government. Neither the United States Government nor any agency thereof, nor any of their employees, makes any warranty, express or implied, or assumes any legal liability or responsibility for the accuracy, completeness, or usefulness of any information, apparatus, product, or process disclosed, or represents that its use would not infringe privately owned rights. Reference herein to any specific commercial product, process, or service by trade name, trademark, manufacturer, or otherwise does not necessarily constitute or imply its endorsement, recommendation, or favoring by the United States Government or any agency thereof. The views and opinions of authors expressed herein do not necessarily state or reflect those of the United States Government or any agency thereof. 